Revista Destaques Acadêmicos, Lajeado, v. 11, n. 3, 2019. ISSN 2176-3070

DOI: http://dx.doi.org/10.22410/issn.2176-3070.v11i3a2019.2060

http://www.univates.br/revistas

\title{
MICROAGULHAMENTO: UMA ALTERNATIVA NO TRATAMENTO PARA O ENVELHECIMENTO CUTÂNEO
}

\author{
Giovana Sinigaglia ${ }^{1}$, Tanise Führ ${ }^{2}$
}

Resumo: Introdução: A pele assim como outros órgãos, ao longo dos anos, sofre alterações fisiológicas que provocam declínio nas suas funções, causando o envelhecimento, que é um conjunto de alterações inevitáveis que ocorrem progressivamente em nosso organismo. $\mathrm{O}$ microagulhamento tem sido estudado e usado para o tratamento de várias patologias e afecções estéticas cutâneas como problemas de pigmentação, rugas, acne e cicatrizes pós queimaduras e no rejuvenescimento facial como parte da terapia de indução de colágeno e veiculação de princípios ativos. A ação do microagulhamento, também conhecida como indução percutânea de colágeno, consiste na geração de múltiplas micropunturas (microlesões) na pele, que resultam em estímulo inflamatório local e, consequentemente, aumentam a proliferação celular (principalmente dos fibroblastos), fazendo com que o metabolismo celular de derme e epiderme seja ativado, favorecendo a síntese de colágeno, elastina e outras substâncias presentes no tecido, restituindo a integridade da pele. Objetivo: Elucidar os efeitos do microagulhamento como forma de tratamento do envelhecimento cutâneo facial. Metodologia: Estudo de revisão integrativa de literatura que apresenta caráter narrativo e descritivo, cuja estruturação da base teórica foi realizada através da pesquisa e análise de livros, periódicos e artigos publicados em revistas científicas na base de dados Periódicos Capes, Scielo, Pubmed e Google Acadêmico, entre os anos de 2011 e 2018, em português e inglês. Foram encontrados 32 artigos que discorriam sobre o tema e destes, foram selecionados 13 artigos para análise neste estudo. Resultados: $\mathrm{O}$ microagulhamento mostrou-se uma intervenção segura e com resultados satisfatórios e surpreendentes para o rejuvenescimento facial, conforme descrito nos artigos analisados. Conclusão: A técnica é eficaz em diversos tratamentos estéticos, seja pela permeação de ativos ou pela estimulação de colágeno, desde que seguidos protocolos de biossegurança necessários, realizado por profissional capacitado em ambiente apto para tal.

Palavras-chave: Microagulhamento. Rejuvenescimento. Colágeno.

1 Centro de Ciências Biológicas e da Saúde.

2 Bacharel em Farmácia. Pós-graduanda em Farmácia Estética. 


\section{INTRODUÇÃO}

O envelhecimento constitui o conjunto de modificações fisiológicas irreversíveis e inevitáveis acompanhadas de uma mudança do nível de homeostasia. O envelhecimento cutâneo participa das alterações involutivas que ocorrem em diversos setores do organismo. Podemos considerar dois tipos distintos, envelhecimento intrínseco ou verdadeiro ou cronológico: esperado, previsível, inevitável e progressivo (as alterações estão na dependência direta do tempo de vida). E envelhecimento extrínseco ou fotoenvelhecimento: surge nas áreas fotoexpostas devido ao efeito repetitivo da ação dos raios ultravioletas (SABATOVICH; KEDE, 2004).

É sabido que um grande número de pessoas tem buscado uma pele com aspecto saudável, viçosa, radiante, livre de manchas e cicatrizes ou qualquer disfunção estética. Alguns tratamentos proporcionam uma estrutura cutânea com mais qualidade e livre de imperfeições (MOREN, 2009).

As intervenções atuais buscam um dano fracionado da pele, possibilitando que a integridade da microrregião adjacente ao trauma mantenha-se integra, favorecendo um tempo de recuperação mais curto e risco diminuído de complicações. O laser $\mathrm{CO}_{2}$ fracionado é um exemplo desta proposta bem como o IPC (Indução Percutânea de Colágeno). É importante notar que mesmo quando o paciente é submetido a procedimentos que removam sobras de pele, atenuando flacidez e rugas, a pele resultante precisa oferecer uma boa aparência e isso se traduz pela renovação tecidual, conceito basilar de uma intervenção fundamentada na neocolagênese e neoangiogênese (LIMA, 2016).

O microagulhamento é uma opção de tratamento para várias disfunções estéticas da pele, como cicatrizes de acne, rejuvenescimento facial, estrias e lipodistrofia ginóide (DODDABALLAPUR, 2009).

O IPC traz uma proposta de um estímulo na produção de colágeno sem provocar a desepitelização total, observadas nas técnicas ablativas. A epiderme e a derme são perfuradas, mas não removidas. Dessa maneira, mesmo rugas profundas resultantes da evolução da elastose na pele fotoenvelhecida, que muitas vezes se comportam como cicatrizes profundas difíceis de serem tratadas por outras técnicas, são melhoradas pelas agulhas. As microagulhas rompem a rigidez e o enrijecimento visualizados frequentemente em rugas profundas estáticas como observadas nas regiões peroral, fronte e região perorbital, especialmente em indivíduos com a pele espessa e seborreica, bem como em tabagistas (LIMA, 2016).

O objetivo desta revisão bibliográfica é elucidar os efeitos do microagulhamento como forma de tratamento do envelhecimento cutâneo facial. 


\section{METODOLOGIA}

Trata-se de um estudo de revisão integrativa de literatura que apresenta caráter narrativo e descritivo, cuja estruturação da base teórica foi realizada através da pesquisa e análise de livros, periódicos e artigos publicados em revistas científicas na base de dados Periódicos Capes, Scielo, Pubmed e Google Acadêmico, entre os anos de 2011 e 2018, em português e inglês. Para a triagem dos artigos foram utilizados os seguintes descritores: "microagulhamento", "envelhecimento facial", "rejuvenescimento facial", "estética facial", "indução percutânea de colágeno". Foram excluídos da pesquisa artigos não relacionados com o assunto abordado. Foram encontrados 32 artigos que discorriam sobre o tema destes, foram selecionados 13 artigos utilizados no estudo.

\section{RESULTADOS}

Tabela 1 - artigos selecionados

\begin{tabular}{|c|c|c|c|}
\hline $\begin{array}{c}\text { Título do estudo/ano } \\
\text { de publicação }\end{array}$ & Autores & Objetivo & Principais resultados \\
\hline \begin{tabular}{|l} 
Estudios e \\
investigaciones - \\
Estimulacion \\
Percutánea de \\
Colágeno com rodillo de \\
Microagujas, 2011 \\
\end{tabular} & $\begin{array}{l}\text { ACEVEDO,Frank Solano } \\
\text { M.D. }\end{array}$ & Revisão de literatura & $\begin{array}{l}\text { O microagulhamento é uma } \\
\text { técnica efetiva na estimulação } \\
\text { percutânea de colágeno. }\end{array}$ \\
\hline \begin{tabular}{|l|} 
Percutaneous collagen \\
induction: minimally \\
invasive skin \\
rejuvenation without risk \\
of hyperpigmentation-fact \\
or fiction?, 2008
\end{tabular} & AUST, M. C. et al. & $\begin{array}{l}\text { Cinqüienta e seis ratos } \\
\text { foram divididos em três } \\
\text { grupos: grupo } A \text { ( } n= \\
\text { 24), terapia de indução } \\
\text { percutânea de colágeno } \\
\text { mais cuidados com a pele; } \\
\text { grupo B }(n=24), \text { cuidados } \\
\text { com a pele; e grupo C }(n= \\
\text { 8) controles. } \\
\end{array}$ & $\begin{array}{l}\text { A terapia de indução } \\
\text { percutânea de colágeno } \\
\text { oferece uma modalidade para } \\
\text { rejuvenescer e melhorar } \\
\text { a aparência e a qualidade } \\
\text { da pele sem risco de } \\
\text { despigmentação. }\end{array}$ \\
\hline $\begin{array}{l}\text { Melasma e } \\
\text { rejuvenescimento facial } \\
\text { com o uso de peeling de } \\
\text { ácido retinóico a } 5 \% \text { e } \\
\text { microagulhamento: Caso } \\
\text { clínico, } 2014 . \\
\end{array}$ & $\begin{array}{l}\text { BERGMANN, C. L. M. S.; } \\
\text { BERGMANN, J.; SILVA, } \\
\text { C. L. M }\end{array}$ & Caso clínico & $\begin{array}{l}\text { O estudo apresentou } \\
\text { resultado satisfatório de } \\
\text { acordo com a queixa da } \\
\text { paciente }\end{array}$ \\
\hline $\begin{array}{l}\text { Microneedling with } \\
\text { dermaroller, } 2009\end{array}$ & DODDABALLAPUR, S. & Revisão de literatura & $\begin{array}{l}\text { É uma modalidade } \\
\text { simples e relativamente } \\
\text { barata que também } \\
\text { pode ser usada para } \\
\text { administração transdérmica } \\
\text { de medicamentos. }\end{array}$ \\
\hline \begin{tabular}{|l|} 
Tratamento de rugas \\
periórbitas por terapia de \\
indução de colágeno,2009
\end{tabular} & FABROCCINI, G. et al. & $\begin{array}{l}\text { Foram incluídos } 20 \\
\text { pacientes ( } 12 \text { mulheres e } \\
\text { oito homens com idades } \\
\text { entre } 50 \text { e } 65 \text { anos) com } \\
\text { rugas periorbitais. Cada } \\
\text { paciente foi tratado com um } \\
\text { aparelho específico em duas } \\
\text { sessões. }\end{array}$ & $\begin{array}{l}\text { O presente } \\
\text { estudo sugere que a TIC possa } \\
\text { ser uma técnica adequada } \\
\text { para melhorar as rugas } \\
\text { periorbitais. }\end{array}$ \\
\hline
\end{tabular}




\begin{tabular}{|c|c|c|c|}
\hline $\begin{array}{c}\text { Título do estudo/ano } \\
\text { de publicação }\end{array}$ & Autores & Objetivo & Principais resultados \\
\hline $\begin{array}{l}\text { Combating photoaging } \\
\text { with percutaneous } \\
\text { collagen induction, } 2008\end{array}$ & $\begin{array}{l}\text { FERNANDES D.; } \\
\text { SIGNORINI, } M .\end{array}$ & Revisão de literatura & $\begin{array}{l}\text { Ao contrário dos tratamentos } \\
\text { ablativos a laser, a epiderme } \\
\text { permanece intacta e não é } \\
\text { danificada. Por esse motivo, } \\
\text { a operação pode ser repetida } \\
\text { com segurança, se necessário, } \\
\text { e também pode ser aplicada } \\
\text { a regiões onde tratamentos a } \\
\text { laser ou peelings profundos } \\
\text { não podem ser realizados. } \\
\end{array}$ \\
\hline $\begin{array}{l}\text { Kinetics of skin resealing } \\
\text { after insertion of } \\
\text { microneedles in human } \\
\text { subjects, } 2011 .\end{array}$ & GUPTA, J. et al. & $\begin{array}{l}\text { utilizou espectroscopia } \\
\text { de impedância elétrica } \\
\text { para realizar os primeiros } \\
\text { experimentos em seres } \\
\text { humanos para analisar a } \\
\text { vedação das propriedades } \\
\text { de barreira da pele após a } \\
\text { inserção de microagulhas. }\end{array}$ & $\begin{array}{l}\text { mostraram que o pré- } \\
\text { tratamento da pele com } \\
\text { microagulhas antes de aplicar } \\
\text { um adesivo transdérmico } \\
\text { oclusivo pode aumentar a } \\
\text { permeabilidade da pele por } \\
\text { mais de um dia, mas, no } \\
\text { entanto, permite que a pele } \\
\text { volte a selar rapidamente após } \\
\text { a remoção do adesivo. } \\
\end{array}$ \\
\hline $\begin{array}{l}\text { Comparative, } \\
\text { randomized, double-blind } \\
\text { study of microneedling } \\
\text { associated with drug } \\
\text { delivery for rejuvenating } \\
\text { the skin of the anterior } \\
\text { thorax region, } 2015\end{array}$ & KALIL, C. L.P.V. & $\begin{array}{l}\text { Estudo randomizado, } \\
\text { duplo-cego, controlado } \\
\text { por placebo, realizado } \\
\text { com } 22 \text { mulheres } \\
\text { submetidas a três sessões } \\
\text { de microagulhamento, } \\
\text { seguidas da aplicação tópica } \\
\text { de um produto de teste } \\
\text { contendo ácido hialurônico } \\
\text { e outros princípios ativos } \\
\text { ou placebo. }\end{array}$ & $\begin{array}{l}\text { A técnica de } \\
\text { microagulhamento associada } \\
\text { à administração transdérmica } \\
\text { de medicamentos utilizados } \\
\text { para rejuvenescimento fornece } \\
\text { uma visão geral da pele da } \\
\text { região anterior do tórax, com } \\
\text { um alto grau de tolerabilidade } \\
\text { e satisfação. }\end{array}$ \\
\hline $\begin{array}{l}\text { Os beneficios do } \\
\text { microagulhamento no } \\
\text { tratamento das disfunções } \\
\text { estéticas, } 2015 .\end{array}$ & $\begin{array}{l}\text { LIMA, A. A, SOUZA, T. } \\
\text { H., GRIGNOLI, L. C. E. }\end{array}$ & Revisão de literatura & $\begin{array}{l}\text { A técnica de } \\
\text { microagulhamento se } \\
\text { mostra eficaz em diversos } \\
\text { tratamentos estéticos, seja } \\
\text { pela permeação de ativos ou } \\
\text { pela estimulação de colágeno } \\
\text { quando usado isoladamente }\end{array}$ \\
\hline $\begin{array}{l}\text { Microagulhamento: } \\
\text { estudo experimental e } \\
\text { classificação da injúria } \\
\text { provocada,2013 }\end{array}$ & $\begin{array}{l}\text { LIMA, E. V. de A., LIMA, } \\
\text { M. de A., TAKANO, D. }\end{array}$ & $\begin{array}{l}\text { Foram realizadas e } \\
\text { biopsiadas áreas de } \\
\text { microagulhamento, em pele } \\
\text { de porco vivo, } \\
\text { com cilindros contendo } 192 \\
\text { agulhas de } 0,5 \text { a } 2,5 \mathrm{~mm} .\end{array}$ & $\begin{array}{l}\text { O estabelecimento de uma } \\
\text { relação entre o comprimento } \\
\text { da agulha utilizada e o dano } \\
\text { provocado na pele facilita a } \\
\text { escolha do instrumento nas } \\
\text { diferentes indicações }\end{array}$ \\
\hline $\begin{array}{l}\text { Subcutaneous } \\
\text { incisionless (subcision) } \\
\text { surgery for the correction } \\
\text { of depressed scars and } \\
\text { wrinkles, } 1995 \text {. }\end{array}$ & $\begin{array}{l}\text { ORENTREICH, D. S., } \\
\text { ORENTREICH, N. }\end{array}$ & $\begin{array}{l}\text { Uma agulha hipodérmica } \\
\text { com três chanfros é inserida } \\
\text { através da pele (daí a } \\
\text { cirurgia "sem incisão") } \\
\text { e suas bordas afiadas } \\
\text { são manobradas sob o } \\
\text { defeito para fazer cortes } \\
\text { subcuticulares ou "cisões". }\end{array}$ & $\begin{array}{l}\text { Essa técnica é útil no } \\
\text { tratamento de várias } \\
\text { depressões, incluindo } \\
\text { cicatrizes e rugas. }\end{array}$ \\
\hline
\end{tabular}




\begin{tabular}{|c|c|c|c|}
\hline $\begin{array}{l}\text { Título do estudo/ano } \\
\text { de publicação }\end{array}$ & Autores & Objetivo & Principais resultados \\
\hline $\begin{array}{l}\text { Severe systemic reaction } \\
\text { associated with skin } \\
\text { microneedling therapy } \\
\text { in } 2 \text { sisters: a previously } \\
\text { unrecognized potential } \\
\text { for complications?, } 2013 .\end{array}$ & PRATSOU, P., GACH, J. & $\begin{array}{l}\text { Duas irmãs, com } \\
\text { idades entre } 34 \text { e } 44 \\
\text { anos, submetidas a um } \\
\text { tratamento minucioso } \\
\text { da pele facial por um } \\
\text { profissional qualificado, de } \\
\text { maneira cruzada, após a } \\
\text { limpeza da pele e aplicação } \\
\text { de creme anestésico tópico }\end{array}$ & $\begin{array}{l}\text { Este é o primeiro relato de } \\
\text { uma reação sistêmica grave } \\
\text { ao rolo de microagulhas } \\
\text { registrado pela FDA em } \\
\text { duas irmãs, destacando a } \\
\text { necessidade de garantia na } \\
\text { microagulhamento de uma } \\
\text { opção sem risco na prática } \\
\text { cosmética. }\end{array}$ \\
\hline $\begin{array}{l}\text { Microneedling: Advances } \\
\text { and widening horizons, } \\
2016 .\end{array}$ & SINGH, A.; YADAV, S. & Revisão de literatura & $\begin{array}{l}\text { Essa técnica pode ser } \\
\text { combinada com outras } \\
\text { técnicas para fornecer } \\
\text { melhores resultados. Em } \\
\text { particular, é uma técnica } \\
\text { muito segura para os tipos de } \\
\text { pele escura, onde o risco de } \\
\text { pigmentação pós-inflamatória } \\
\text { é muito alto com outras } \\
\text { técnicas que danificam a } \\
\text { epiderme. }\end{array}$ \\
\hline
\end{tabular}

O processo de envelhecimento, intrínseco e extrínseco, oferece à face uma redução considerável de volume. Observam-se reabsorção óssea, redução de massa muscular, redistribuição da gordura, frouxidão ligamentar, e a pele, que como envelope recobre toda essa estrutura, fica folgada, frouxa, resultando em sobras, flacidez e rugas finas e profundas. A derme e a epiderme, que também sofrem com a degeneração, afinam, acentuando ainda mais o aspecto resultante do tempo e do estresse oxidativo (SABATOVICH; KEDE, 2004).

O envelhecimento da pele pela radiação ultravioleta é manifestado por desorganização das fibras de colágeno e alteração da composição da elastina, ocorrendo inclusive a diminuição do número de fibroblastos que fabricam essas proteínas (MAIO, 2004).

O colágeno é o componente fibrilar principal do tecido conectivo e a proteína extracelular mais importante do corpo humano (HARRIS, 2009). O colágeno representa cerca de $25 \%$ de todas as proteínas. É a proteína mais abundante dos tecidos animais (MAIO, 2004). É a maior e mais importante proteína estrutural da pele, responsável pela firmeza e elasticidade cutânea (RIBEIRO, 2006). A capacidade de divisão do fibroblasto é limitada, com o envelhecimento a velocidade de divisão diminui, comprometendo a síntese proteica da matriz extracelular provocando alterações de elasticidade e de sustentação do tecido, resultando em alterações do relevo cutâneo (HARRIS, 2009).

O IPCA (microagulhamento) um é procedimento com indicações clínicas variadas para o tratamento da pele, como rejuvenescimento, acne, cicatrizes hipertróficas, rugas, estrias, pigmentação, etc. O princípio do microagulhamento foi citado pela primeira vez com o nome de subcision, o procedimento foi realizado para a correção de cicatrizes deprimidas e rugas utilizando agulhas cirúrgicas 
para estimular a produção de colágeno (ORENTREICH; ORENTREICH, 1995). Sua técnica surgiu na década de 90 na Alemanha sob a marca Dermarroler ${ }^{\mathrm{TM}}$, porém apenas em 2006 a ideia deste equipamento começou a se difundir por todo o mundo. Dermarroler ${ }^{\mathrm{TM}}$ consiste em um rolo em forma de tambor pequeno cravejado com diversas agulhas finas $(0,1 \mathrm{~mm}$ de diâmetro), feitos de aço inoxidável cirúrgico, em diferentes milímetros de comprimento $(0,5 \mathrm{a}$ $3,0 \mathrm{~mm}$ ) posicionados paralelamente em várias fileiras. Hoje existem diversas marcas no mercado. Para o remodelamento do colágeno, é necessário que as agulhas cheguem à profundidade de 1,0 a 3,0 mm, de modo a atingir a derme; entretanto, apenas de $50 \%$ a $70 \%$ das agulhas penetram durante o rolamento, significando que as agulhas para remodelamento de colágeno devem ter no mínimo 1,5 mm (LIMA; LIMA; KAKANO, 2013).

$\mathrm{O}$ roller provoca micro lesões na pele, gerando um processo inflamatório local, com intensificada proliferação celular (principalmente dos fibroblastos), fazendo com que aumente o metabolismo celular deste tecido (derme e epiderme), incrementando a síntese de colágeno, elastina e outras substâncias presentes no tecido, restituindo a integridade da pele (KLAYN; LIMANA; MORAES, 2013).

Desta forma, o procedimento é realizado por meio da perfuração do estrato córneo, sem danificar a epiderme, resultando na perda da integridade cutânea, o que inicia o processo de cicatrização e culmina com a formação de colágeno tipo I, que tem efeito no rejuvenescimento da pele. Esse processo permite a liberação de fatores de crescimento, que vai incentivar a produção de colágeno e elastina na derme papilar (KALIL; CAMPOS; CHAVES; PITASSI; CIGNACHI, 2015).

Diversos estudos têm sido conduzidos para demonstrar que o microagulhamento proporciona o drug delivery (GUPTA et al., 2011).

O desenvolvimento de fármacos mais sofisticados exigiu a necessidade de métodos mais sofisticados para aumentar a absorção e penetração dos princípios ativos. No entanto a permeação transdérmica é severamente limitada pela incapacidade da grande maioria dos medicamentos para atravessar a pele, devido à grande barreira imposta pela camada exterior do estrato córneo da pele (GAMA, 2011).

Outra função da técnica de microagulhamento seria potencializar a permeação de princípios ativos cosmetológicos, uma vez que os microcanais facilitam a absorção do ativo, aumentando a penetração de moléculas maiores em até $80 \%$. É a partir dos fatores de crescimento que ocorre essa estimulação da formação de colágeno e elastina na derme papilar (LIMA; SOUZA; GRIGNOLI, 2015).

Ativos antienvelhecimento podem ser incorporados aos cosmecêuticos, tais como vitaminas, minerais, botânicos, peptídeos e fatores de crescimento, a fim de se obterem benefícios clínicos (BAGATIN, 2008). 
A IPCA conforme demonstrado no Brasil por Emerson Lima (2016), propõe uma melhora na textura, coloração e relevo da pele danificada com microagulhas cujo comprimento varia de 0,25 a 2,5 $\mathrm{mm}$. A escolha de que comprimento de agulha usar depende do grau da injúria que desejamos provocar: leve, moderada ou profunda. Em se tratando de pele envelhecida, deve-se considerar os seguintes itens:

- Espessura da pele: as peles muito finas irão oferecer pouca resistência a comprimento de agulhas menores, quando comparada às peles espessas (pacientes com histórico de acne e presença de cicatrizes apresentam a pele mais espessa e com reentrâncias que dificultam o rolamento das microagulhas, comprometendo a uniformidade de sua penetração, fato igualmente observados em tabagistas e em peles com fotodano substancial - a elastose);

- Profundidade das rugas: as mais rasas são mais facilmente tratadas, obtendo-se bons resultados com agulhas de comprimento de $1,5 \mathrm{~mm}$. Já as rugas profundas necessitam ser descoladas, sendo necessárias agulhas com comprimentos de 2,0 a 2,5 mm;

- Flacidez: é mais fácil de tratar a flacidez facial que a corporal, visto que o coxim adiposo do corpo oferece resistência à penetração da agulha. Pode-se optar por várias sessões com comprimento de agulha menor e intervalo de 1 mês ou uma única sessão com injúria profunda;

- Intervenção sequenciada: o tratamento do envelhecimento da pele pode ser estabelecido em sessões, uma por mês, com adição de ativos (vitamina C, vitamina E, ácido tranexânico, fatores de crescimento, lipossomos, entre outros) com propriedades estimuladoras de colágeno. Assim, as microagulhas criam canais, quebrando a barreira epidérmica, favorecendo a permeação desses ativos, não sendo necessário utilizar, nesses casos, agulhas com comprimento de agulha maior que $1,5 \mathrm{~mm}$;

- Injúria profunda: proposta oferecida quando a pretensão é oferecer bons resultados em uma única sessão, abordando assim rugas, flacidez e perda de volume em uma única intervenção. Para tanto, utiliza-se comprimento de agulhas de $2,5 \mathrm{~mm}$ sob anestesia infiltrativa. Caso se deseje realizar uma segunda intervenção, é necessário esperar pelo menos noventa (90) dias para a estabilização dos resultados.

\subsection{Fases de cicatrização por ação do microagulhamento}

Com esta terapia a pele passa por três fases no processo de cicatrização. Na fase de inflamação (fase 1), que se inicia logo após a lesão, as plaquetas liberam fatores quimiotáticos que provocam a invasão de outras plaquetas, neutrófilos e fibroblastos. Na fase de proliferação (fase 2), os neutrófilos são substituídos 
por monócitos que se transformam em macrófagos e liberam vários fatores de crescimento, incluindo fator de crescimento derivado de plaquetas (PDGF), fator de crescimento fibroblástico (FGF), fator de crescimento transformador (TGF-b e TGF-a), os quais estimulam a migração e a proliferação de fibroblastos. Ocorre a mobilização de queratinócitos para cobrir a lacuna da membrana basal; eles começam a produzir os componentes para restabelecer a membrana basal com laminina e colágeno tipo IV e VII. Os queratinócitos começam a proliferar e liberam fatores de crescimento para promover a reposição do colágeno pelos fibroblastos. Novos vasos sanguíneos são formados e o colágeno tipo III é a forma dominante na fase inicial da cicatrização. $O$ remodelamento tecidual (fase 3) é feito principalmente pelos fibroblastos, continuando por meses após a lesão. O colágeno tipo III é depositado na derme, logo abaixo da camada basal da epiderme, sendo gradualmente substituído pelo colágeno tipo I (FABBROCINI et al., 2009).

\subsection{Técnicas de aplicação}

A IPCA produz micro orifícios longos o suficiente para romper a integridade da barreira cutânea e atingir a derme, dependendo do comprimento da agulha, desencadeando um estímulo inflamatório com futura formação de um colágeno novo com o sangramento provocado. Devido a isso, recomendase um preparo prévio da pele que deve se iniciar, preferencialmente duas (2) a quatro (4) semanas antes da realização do procedimento, que consiste na associação de agentes tópicos. A pele bem preparada proporciona resultados mais efetivos e uniformes ao tratamento, sendo possível também minimizar possíveis efeitos adversos tais como hipo ou hiperpigmentação pósinflamatória, eritema persistente, bem como a reepitelização mais rápida e melhora da cicatrização (LIMA, 2016).

O preparo da pele visa promover alterações cutâneas capazes de favorecer o resultado final do procedimento, tais como: diminuição da barreira cutânea, tornando-a menos espessa para a penetração dos ativos; minimizar ocorrência de hiperpigmentação pós-inflamatória; favorecimento do processo de reepitelização e cicatrização; diminuição da ocorrência de hipocromia residual pós-procedimento; reduzir aumento de produção de sebo ou desenvolvimento de quadros de acne pós-procedimento (LIMA, 2016).

O procedimento é invasivo, ainda que minimamente, portanto deve-se tomar medidas de asséptica e antisséptico (ACEVEDO, 2011). Antes de iniciar o procedimento, utiliza-se anestésico tópico na área a ser tratada por um período de 30 a 45 minutos (GAMA, 2011). O tipo de anestesia utilizada varia de acordo com o comprimento das agulhas, que deve ser escolhido conforme o tipo de pele a ser tratada e o objetivo final do procedimento (LIMA et al., 2013). Após, é realizada a antissepsia, sendo na sequência realizada a aplicação do roller com microagulhas (GAMA, 2011). 
A pressão vertical exercida sobre o roller, não deve ultrapassar $6 \mathrm{~N}$, pois força superior pode levar danos a estruturas anatômicas mais profundas e mais dor que o esperado ao paciente. Recomenda-se posicionar o aparelho entre os dedos indicador e polegar como se estivesse segurando um "háshi" e controlar a força exercida com o polegar. Os movimentos de vai e vem devem guiar-se por padrão uniforme de petéquias em toda a área tratada. Para isso, entre dez (10) a quinze (15) passadas em uma mesma direção e pelo menos 4 cruzamentos na área de rolagem são suficientes. Teoricamente quinze (15) passadas provocam dano de 250-300 punturas $/ \mathrm{cm}^{3}$ (MOREN, 2009).

$\mathrm{O}$ aparecimento de petéquias varia com a espessura da pele tratada e o comprimento da agulha usada. As peles mais finas e frouxa, comumente fotoenvelhecida, apresentará padrão uniforme de petéquia mais precocemente do que a pele espessa e fibrosada (LIMA et al., 2013).

Lima, Lima e Takano (2013) classificam as microlesões como leves, quando são utilizadas agulhas com comprimento de 0,25 e 0,5 mm; moderadas, com uso de agulhas de 1,0 e 1,5 mm; e profundas, quando se utilizam agulhas de 2,0 e $2,5 \mathrm{~mm}$. No tratamento de rugas finas e melhora de brilho e textura da pele, é indicado o uso de injúrias leves para administração de ativos; para tratamento de flacidez cutânea, rugas médias e rejuvenescimento, indicase o uso de injúrias moderadas; já para tratamento de cicatrizes deprimidas distensíveis, estrias e cicatrizes onduladas e retráteis, o uso de injúrias profundas é o mais indicado.

Fernandes e Signorini (2008) indicam o tratamento de microagulhamento com agulhas de $1 \mathrm{~mm}$ para restauração da tensão da pele nos estágios adiantados do envelhecimento facial.

\subsection{Efeitos pós-ipca}

O microagulhamento está associado a uma baixa taxa de efeitos adversos. Exame histológico realizado 24 horas após o tratamento demonstra uma epiderme intacta e nenhuma mudança no número de melanócitos, resultando em tempo de inatividade limitado e risco mínimo de despigmentação (AUST et al., 2008).

Efeitos adversos são raros e temporários no pós-procedimento, sendo o eritema o mais comum (DODDABALLAPUR, 2009). Um estudo de caso relatou duas irmãs que desenvolveram reações de hipersensibilidade após microagulhamento, sendo possivelmente reações alérgicas às próprias agulhas (PRATSOU; GACH, 2013).

Outros efeitos esperados e adversos após tratamento de IPCA incluem edema (variando de modesto a intenso, dependendo do comprimento de agulha utilizado na intervenção e a metodologia instituida pelo operador; hematoma, petéquias e púrpuras; crostas (que ocorrem mais frequentes quando provocada injúria profunda); hiperpigmentação pós-inflamatória (que pode 
estar associada à falta de preparo de pele pré-tratamento ou em peles com mais melanina ou com adição de ativos com potencial ablativo); descamação (para injúrias leve a moderada é esperada uma descamação leve entre 48 a 78 horas e para injúria profunda, ocorre mais tardiamente, entre quinto e sétimo dia); dor, ardor e sensibilização (recomenda-se manter a região sempre hidratada, o que favorece o processo de cicatrização) (LIMA, 2006).

Infecções podem ocorrer em pacientes com histórico de herpes recalcitrante, recomendando tratamento preventivo. Já o risco de infecção bacteriana ocorre pela contaminação do instrumental utilizado (LIMA, 2006).

\subsection{Contraindicações do microagulhamento}

As contraindicações para o uso deste método são: formas raras e severas de cicatrizes queloidianas; diabetes; doenças neuromusculares; distúrbio hemorrágico; doenças vasculares; corticoterapia aguda e crônica; terapêutica aguda ou crônica com anticoagulante; presença de cânceres de pele; verrugas; ceratose solar; infecção cutânea; pele sensível ou com alguma patologia; gravidez; acne aguda; 9 herpes ativa; uso de Roacutan; rosácea ativa; alergia (metal ou cosmético); pele queimada de sol (TORQUATO, 2014).

\section{DISCUSSÃO}

Tratamentos ablativos, como peelings químicos médios e profundos, propiciam incontestável estímulo na produção de colágeno, o que resulta na atenuação de rugas, flacidez, melhoria da textura, brilho e coloração da superfície cutânea, atenuação substancial do fotodano. Procedimentos com associação da abrasão cirúrgica com TCA (tricloroacético) 35\% (ativo cáustico), resulta em recuperação longa e tecido mais sensível à luz, sujeito à hiperpigmentação pós-inflamatória e fotossensibilidade, somado ao risco de complicações como formação de cicatrizes hipertróficas, eritema persistente e discromias. A epiderme é removida, ocorre uma retificação das papilas dérmicas e o tecido cicatricial resultante é constituído de feixes espessos de colágeno orientado paralelamente, diferentemente da rede de entrelaçamento do colágeno encontrado na pele normal (LIMA, 2016).

Lima, Lima e Takano (2013) verificaram o uso do microagulhamento como forma de veicular ativos com Retinol e Vitamina C para fim de rejuvenescimento. Observaram que o uso isolado dessa técnica promove melhora na textura, na coloração e no brilho de peles envelhecidas. Neste artigo, os autores descrevem o processo de injúria tecidual decorrente do uso de diferentes níveis de agulhamento, sendo classificado entre leve (com agulhas de 0,25 a $0,5 \mathrm{~mm}$ ), moderado (com agulhas de 1,0 a 1,5mm) e profundo (com agulhas de 2,0 a 2,5mm). A injúria tecidual leve comumente é observada em pacientes que apresentam quadros de rugas finas e brilho excessivo; já o nível moderado ocorre em pacientes que apresentam flacidez cutânea, rugas 
médias e envelhecimento; e, por sua vez, o processo de injúria profunda ocorre em pacientes que possuem estrias e cicatrizes.

Fernandes e Signorini (2008) demonstraram que a técnica de microagulhamento é eficiente no tratamento de sinais de envelhecimento, assim como nos tratamentos de cicatrizes de acne e de queimaduras.

Reforçando a ideia de que a indução percutânea de colágeno é efetiva no tratamento do envelhecimento, Fabbrocini et al. (2011) realizaram um procedimento a fim de rejuvenescer a pele do pescoço de oito indivíduos. Com duas sessões de microagulhamento, observaram uma melhora de $90 \%$ dos pacientes, comprovando que o tratamento gera resultados positivos.

Segundo Fabbrocini et al. (2014) avaliaram que a técnica de microagulhamento isolada em cicatrizes de acne de 60 pessoas entre os fototipos de I a VI. Elas foram divididas em grupos A (fototipos I e II), B (fototipos III a V) e C (fototipo VI) e passaram por três sessões de microagulhamento com intervalos mensais. Os pesquisadores concluíram que a técnica atua positivamente em todos os fototipos sem apresentar risco de despigmentação.

Bergmann, Bergmann e Silva (2014), demonstraram que o microagulhamento também se mostrou eficaz no tratamento de melasma e envelhecimento associado ao uso de ativos cosméticos. Segundo os autores, foi possível observar uma melhora significativa nas duas disfunções após duas sessões de microagulhamento associado a $2 \mathrm{ml}$ de fatores de crescimento EGF e TGF e ácido tranexâmico em solução. Associada a essa técnica, também foram realizadas, alternadamente, duas sessões de peelingcom ácido retinóico a 5\% em intervalos de vinte e um (21) dias entre as sessões. No entanto, são necessários mais estudos sobre a associação dessas técnicas, visto que foi realizado apenas um estudo de caso.

Para Aust et al. (2008), em estudo realizado na Alemanha com indivíduos apresentando rugas, cicatrizes e estrias, foram realizadas de uma (1) até quatro (4) sessões de microagulhamento com aplicação tópica de vitamina A e C. A avaliação dos pacientes revelou uma melhoria de $60-80 \%$ na aparência de sua pele, enquanto que a evidência empírica por exames histológico em vinte (20) pacientes demonstrou umaumentosignificativodecolágenoeelastinaemseis(6)mesesapós o tratamento e um aumento de $40 \%$ na espessura da epiderme meses após o tratamento (WIZE, 2009).

Para Kalil et al. (2015), o microagulhamento é bastante eficaz; porém, é necessária a associação com ativos específicos para drug delivery para que se obtenham resultados em grau de rejuvenescimento global avançado.

Segundo Singh e Yadav (2016), o microagulhamento em peles maduras é realizado, devido aos efeitos gerados após o tratamento como a pele com aparência "juvenil", já que reduz as linhas finas e as rugas, a redução do tamanho do poro, e o aumento a elasticidade e flexibilidade do tecido. Esses efeitos de rejuvenescimento devem-se a partir da injúria causada pelas 
microperfurações, que levam a formação de novas fibras de colágeno (tipo I, III, VII) e elastina além da reorganização das fibras antigas, assim como o processo de angiogênese, com a formação de novos vasos.

\section{CONCLUSÃO}

De acordo com a pesquisa desenvolvida, pode-se inferir que o microagulhamento é uma intervenção segura e com resultados satisfatórios e surpreendentes para o rejuvenescimento facial, além de muitas outras patologias e afecções estéticas. A técnica de microagulhamento mostra-se eficaz em diversos tratamentos estéticos, seja pela permeação de ativos ou pela estimulação de colágeno, desde que seguidos protocolos de biossegurança necessários, realizado por profissional capacitado e em ambiente apto para tal.

\section{REFERÊNCIAS}

ACEVEDO, F. S. M. D. Estudios e investigaciones - Estimulacion Percutánea de Colágeno com rodillo de Microagujas. Revista de La Asociacion Científica Colombiana de Medicina Estética. Volume 02 no 01, p 28-32, 2011.

AUST, M. C. et al. Percutaneous collagen induction: minimally invasive skin rejuvenation without risk of hyperpigmentation-fact or fiction? Plast Reconstr Surg; 122:1553-63, 2008.

BAGATIN, E. Envelhecimento cutâneo e o papel dos cosmecêuticos. Boletim dermatológico UNIFESP, São Paulo, Ano V, n. 17, p. 1-4, 2008.

BERGMANN, C. L. M. S.; BERGMANN, J.; SILVA, C. L. M. da. Melasma e rejuvenescimento facial com o uso de peeling de ácido retinóico a $5 \%$ e microagulhamento: Caso clínico. 2014.

DODDABALLAPUR, S. Microneedling with dermaroller. Journal of Cutaneous and Aesthetic Surgery, Bangalore, Karnataka, India, v. 2, n. 2, p. 110-111, jul / dez 2009.

FABBROCINI, G. et al. Tratamento de rugas periórbitas por terapia de indução de colágeno - Surgical \& Cosmetic Dermatology. Volume 1, No 3, 2009.

FABBROCINI, G. et al. Skin needling in the treatment of the aging neck. SKINmed Journal: Dermatology for the Clinician, Sea Bright, USA, v. 9, n. 6, p. 347-351, nov. / dez. 2011.

FABBROCINI, G. et al. Percutaneous collagen induction: an effective and safe treatment for post-acne scarring in different skin prototypes. Journal of Dermatological Treatment, Sea Bright, USA, v. 25, n. 2, p. 147-152, abr. 2014. 
FABBROCINI, G. et al. Skin needling to enhance depigmenting serum penetration in the treatment of melasma. Plastic Surgery International, Hindawi Publishing Corporation, v. 2011, p. 1-7, abr. 2011a.

FERNANDES D.; SIGNORINI, M. Combating photoaging with percutaneous collagen induction. Clinics in Dermatology, Elsevier B.V., v. 26, n. 2, p. 192-199, mar. /abr. 2008.

GAMA, R. Dermaroller - máscara de ascorbosilane C. Revista Biotec, ano 03, $\mathrm{n}^{\mathrm{o}}$ 08, p 19. 2011.

GUPTA, J. et al. Kinetics of skin resealing after insertion of microneedles in human subjects. J Control Release.154(2):148-55, 2011.

HARRIS, M. I. N. de C. Pele - Estrutura, Propriedades e Envelhecimento. $3^{\text {a }}$ Edição Revisada e ampliada. Editora Senac - São Paulo, 2009.

KALIL, C. L. P. V. Comparative, randomized, double-blind study of microneedling associated with drug delivery for rejuvenating the skin of the anterior thorax region. SurgCosmetDermatol. 2015;7(3):211-216.

KLAYN, A. P.; LIMANA, M. D.; MORAES, L. R. S. Microagulhamento como agente potencializador da permeação de princípios ativos corporais no tratamento de lipodistrofia localizada: estudo de casos. In: Encontro internacional de produção científica CESUMAR - EPCC, 8., 2013, Maringá. Anais Eletrônicos. Maringá: Editora Cesumar, 2013. p. 1-5.

LIMA, A. A, SOUZA, T. H., GRIGNOLI, L. C. E. Os benefícios do microagulhamento no tratamento das disfunções estéticas. Revista Científica da FHO. UNIARARAS v. 3, n. $1 / 2015$.

LIMA, E. V. de A., LIMA, M. de A., TAKANO, D. Microagulhamento: estudo experimental e classificação da injúria provocada. SurgCosmetDermatol; 5(2):110-4, 2013.

LIMA, E. de A. IPCA Indução percutânea de colágeno com agulhas. Editora Guanabara Koogan. 2016.

MAIO, M. de. Tratado de Medicina Estética. Volume I. Rocca. São Paulo, 2004.

MOREN, S. A. SPAs e salões de beleza terapias: Terapias Passo a Passo. Cengage, 2009.

ORENTREICH, D. S., ORENTREICH, N. Subcutaneous incisionless (subcision) surgery for the correction of depressed scars and wrinkles. Dermatol Surg. 21(6):6543-9, 1995. 
PRATSOU, P., GACH, J. Severe systemic reaction associated with skin microneedling therapy in 2 sisters: a previously unrecognized potential for complications? J Am Acad Dermatol 2013; 68: AB219, 2013.

RIBEIRO, C. Cosmetologia aplicada a dermocosmética. Pharmabools. São Paulo, 2006.

SABATOVICH, O.; KEDE, M. P. V. Dermatologia Estética. Editora Atheneu. São Paulo, Rio de Janeiro, Ribeirão Preto, Belo Horizonte, 2004.

SINGH, A.; YADAV, S. Microneedling: Advances and widening horizons. Indian Dermatology Online Journal. N 7, v. 4, p. 244-254, 2016.

TORQUATO, G. - Microagulhamento: terapia de indução de colágeno provoca microferimentos na pele para preencher marcas. - Ler e Saúde, 2014.

WIZE, I. M. 8 Briefing for the Scientific Community - Therapy. 2009. 